\title{
Glandular cardiac myxoma: case report with literature review
}

\author{
S.-M. Yuan \\ $1^{\text {st }}$ Hospital of Putian, Teaching Hospital, Fujian Medical University, Putian, Fujian Province, People's Republic of China
}

[Received 24 November 2013; Accepted 11 January 2014]

Glandular cardiac myxoma is rare, representing only 5\% of cardiac myxomas. A 51-year-old female developed embolic events caused by left atrial myxoma. She underwent myxoma resection and had an uneventful postoperative course. Histology of the resected myxoma revealed a glandular cardiac myxoma. In this article, the peculiar case was presented and the origin of cardiac myxoma was discussed. (Folia Morphol 2014; 73, 3: 374-382)

Key words: cell differentiation, heart neoplasms, immunohistochemistry

\section{INTRODUCTION}

Cardiac myxomas (CMs) are the most common primary heart tumours in adults, accounting for $50 \%$ of the cases [65]. Diverse clinical manifestations and malignant behaviours of this benign neoplasm have attracted considerable interest [33]. Multipotential undifferentiated mesenchymal cells are believed to be the origin of CM [30]. Instant studies revealed that CMs are neoplastic rather than thrombogenic in origin, as mesenchymal cells represent divergent differentiations $[1,14]$. Pathological changes representing differentiations, such as chondrification, calcification, ossification, extramedullary haematopoiesis, thymic remnants and mucin-producing glands occasionally found in $\mathrm{CM}$, indicating a neoplastic origin arising from foregut remnants [76]. Immunohistochemical evidences of indifferentiated mesenchymal cells, non-metastatic nature in most cases [16], gland-like, epithelium-lined cystic and tubular spaces with features of the mesothelioma [22], and ultrastructurally proved active secretional structures [21, 23, 32] also supported the neoplastic origin theory. Nevertheless, the organising cardiac intramural thrombi and papillary endocardial lesions of histological featu- res similar to those of $\mathrm{CM}$ challenged the neoplastic origin hypothesis [64], and the exact origin of CM still remains disputable [3]. Furthermore, histology, histochemistry and immunohistochemistry of CM have been sufficiently studied; whereas pertinent aspects of glandular CM have not, due to the rarity of the glandular differentiation. As estimated in the literature, glandular CM are rare representing about $5 \%$ of CM [38]. The aim of this article is to present the structural and immunohistochemical features of glandular CM by a case report with literature review, and to further discuss the origin of CM.

\section{CASE REPORT}

A 51-year-old female had abrupt vision loss 6 months prior to current admission. She was then referred to a nearby hospital and was diagnosed with "top of the basilar" syndrome and cardiogenic shock caused by a left atrial myxoma. She also developed multiple arterial embolisms of her lower extremities involving bilateral anterior tibial, bilateral posterior tibial, right popliteal and bilateral dorsal arteries as evidenced by ultrasonography. Her condition was gradually stabilising after prolonged treatment. She 
was recently referred to this hospital for surgical treatment of left atrial myxoma. After admission, the diagnosis of left atrial myxoma was confirmed by echocardiography and chest computed tomography. Her vital signs were normal. Precordial systolic murmurs were only audible in a sitting position on the $5^{\text {th }}$ morning after admission. She was conscious but apathy, with bilateral blepharoptoses and poor pupillary light reactions. Her left pupil was $4 \mathrm{~mm}$ and right pupil was $2 \mathrm{~mm}$ in diameter. She showed poorly upward, downward and adducted eye movements, and slightly decreased right lower limb muscle strength but symmetrical deep tendon reflexes.

Left atrial myxoma resection was performed under cardiopulmonary bypass. During the operation, the myxoma was found to be originated from the free wall of the left atrium. The myxoma was resected en bloc, and the iatrogenic atrial wall defect was repaired with an autologous pericardial patch. She had a delayed aesthetic awakening until postoperative hour 13.5 with no new neurological sequelea. She had an uneventful postoperative course and was discharged home on postoperative day 19.

The myxoma was grossly villous, polypoid, and loosely lobulated with smooth, glistening surface, measuring $4.5 \times 4.5 \times 3.0 \mathrm{~cm}$ in size (Fig. 1). The myxoma was brown in colour, uncapsulated and broadbased without a pedicle. On the cut surface, the myxoma was gelatinous and semitransparent with partially haemorrhagic and cystic regions. Microscopically, the myxoma was composed predominantly of scattered stellate, spindle-shaped, or polygonal myxoma cells, with small endothelial vascular channels lying in a loose myxoid stroma.

Glandular structures were focally located at the base of the myxoma dispersed in the loose amorphous stroma (Fig. 2). Some glands had obvious lumina, while others did not. Gland fusions were noted (Fig. 3). In overall, the glandular structures were well-developed by irregularly arranged single columnar, cuboid, or flat cells. There were a few goblet cells with cytoplasmic mucin vacuoles. No obvious atypia, mitosis, or necrosis was present.

The immunohistochemical stains utilised the antibodies against pan-cytokeratin (CK) (AE1/AE3), vimentin, CK7, CK20, epithelial membrane antigen (EMA), smooth muscle actin (SMA), Ki-67, Factor VIII, desmin, S100, oestrogen receptor, c-erbB2, B-cell lymphoma 2 (Bcl-2), myogenin, melanoma marker HMB45, cellular tumour antigen p53, lambda light

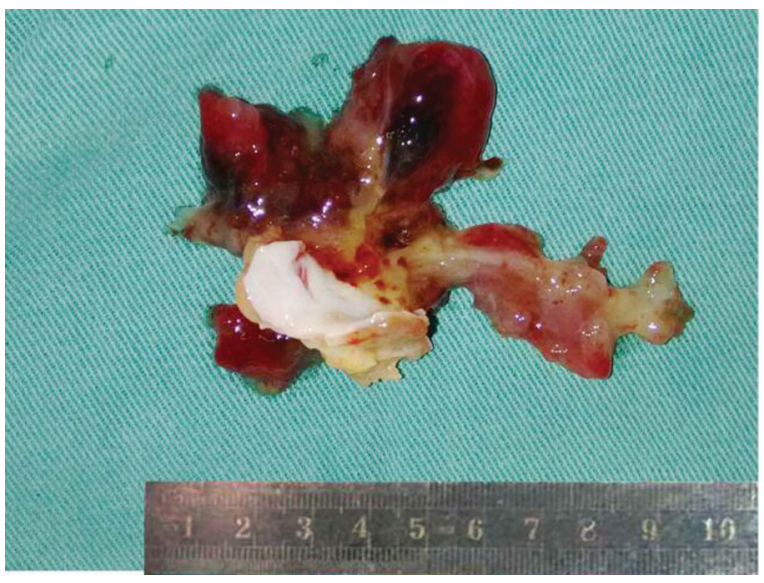

Figure 1. Gross appearance of the myxoma, which was grossly villous, polypoid.

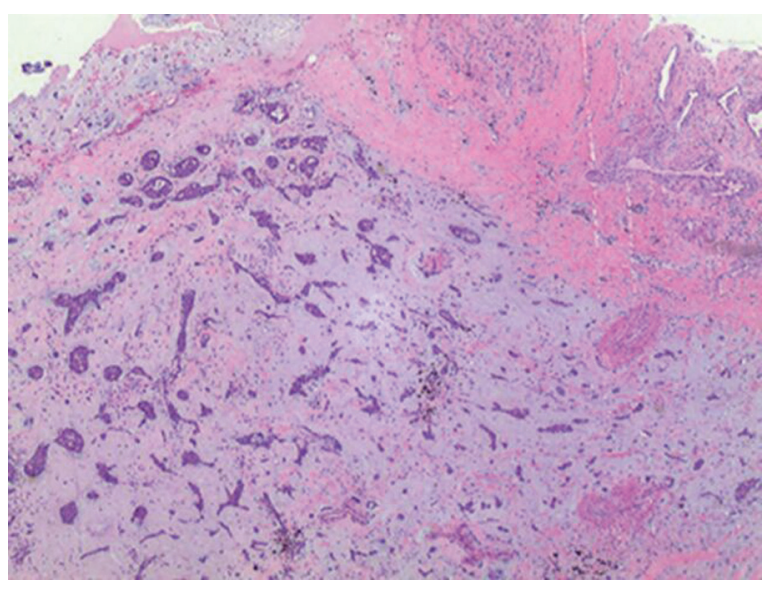

Figure 2. Glandular structures were focally located at the base of the myxoma; $\mathrm{HE} \times 25$.

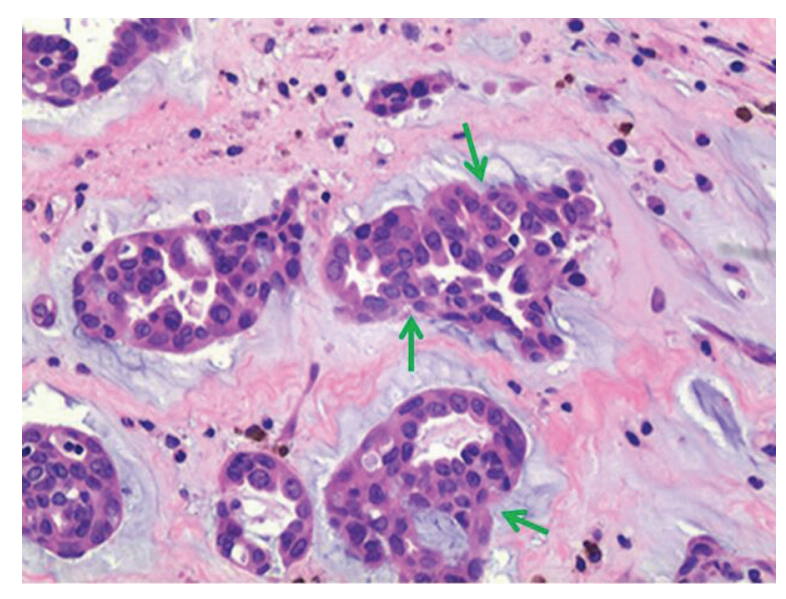

Figure 3. Gland fusions (arrows); $\mathrm{HE} \times 400$.

chain, CD3, CD20, CD34, CD56, CD57, CD68, CD79 $\alpha$, CD99, CD138, proliferating cell nuclear antigen and 


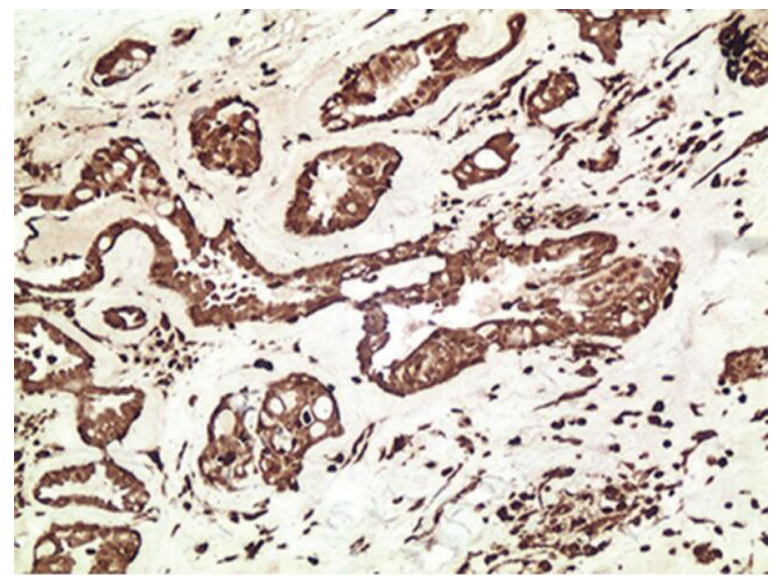

Figure 4. Immunohistochemical expression of vimentin in glandular structures; En Vision $\times 400$.

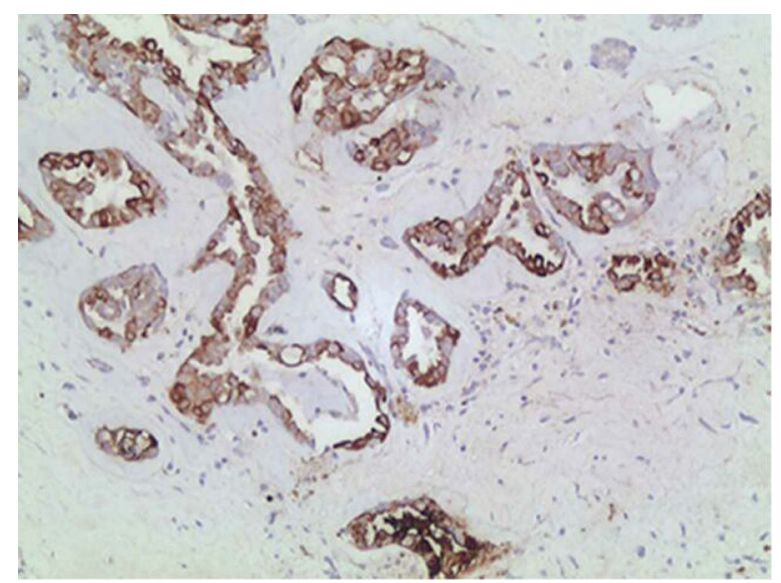

Figure 5. Immunohistochemical expression of epithelial membrane antigen in glandular structures; En Vision $\times 400$.

cyclin D. The glandular structures were strongly and diffusely immunoreactive to vimentin (Fig. 4) and EMA (Fig. 5), moderately to carcinoembryonic antigen (CEA) (endothelium-lined area) (Fig. 6) and CD34 (glandular epithelium) (Fig. 7) and weakly and scatteredly immunoreactive to CD3 (Fig. 8), CD20 (Fig. 9) and Ki-67 (Fig. 10), but negatively immunoreactive to SMA, Factor VIII, pan-CK, desmin, S100, oestrogen receptor, c-erbB2, Bcl-2, myogenin, HMB45, P53, lambda light chain, CD56, CD57, CD68, CD79 $\alpha, C D 99$, CD138, proliferating cell nuclear antigen and cyclin D.

\section{DISCUSSION}

A comprehensive literature collection of glandular CM was made in PubMed, Google and Baidu search engines, Highwire Press, Airitilibrary, LILACs,

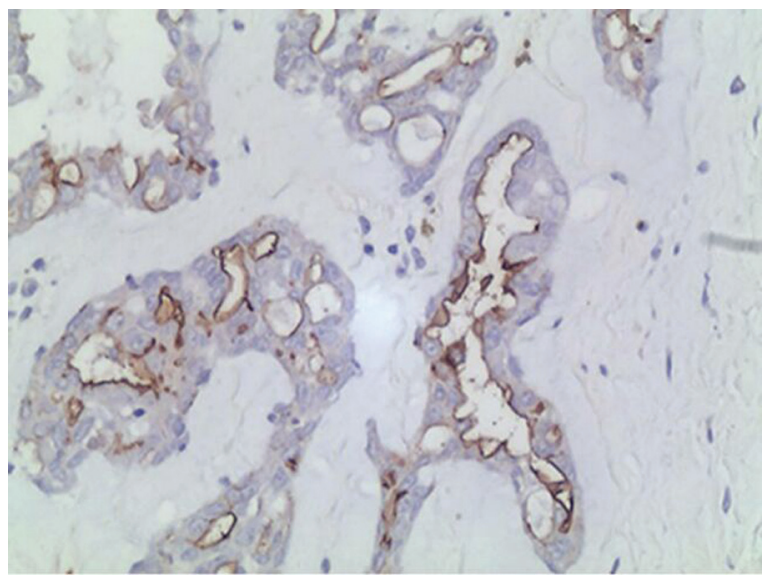

Figure 6. Immunohistochemical expression of carcinoembryonic antigen in glandular structures; En Vision $\times 400$.

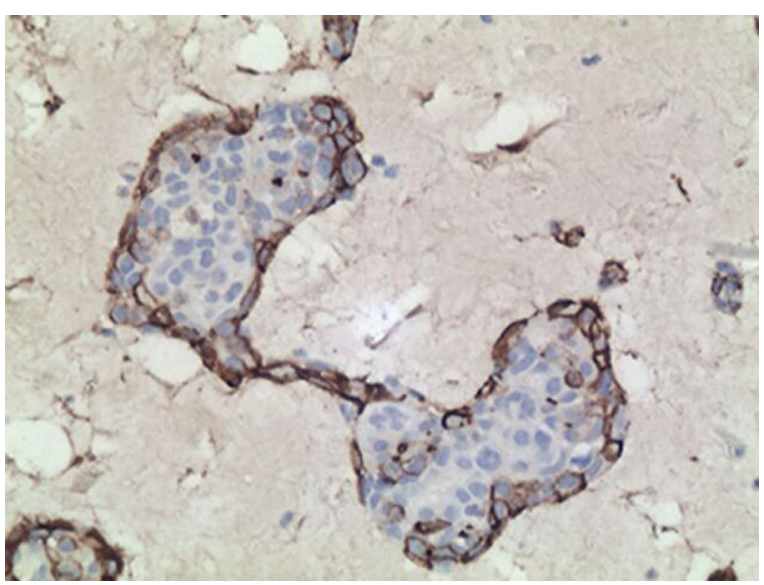

Figure 7. Immunohistochemical expression of $\mathrm{CD} 34$ in glandular structures; En Vision $\times 400$.

sinomed.imicams.ac.cn/jp/ and Chinese Medical Citation Index $(\mathrm{CMCl})$. The search terms included "heart myxoma", "cardiac myxoma", "atrial myxoma", "valvular myxoma", "glandular component", "glandular structure" and "gland-like structure", and the search ended on December 31, 2013. A total of 124 reports were collected including 108 (e-)journal articles, 9 book chapters and 9 web pages. Of them, 54 reports describing $\mathrm{CM}$ without any glandular components, or narrating glandular differentiation of $\mathrm{CM}$ without patient information, such as review articles, book chapters and majority of the web pages, were excluded from the statistical analysis of this study. Alternative exclusion criteria included duplicate publications $[20,26,28,46,48]$, and original articles with only patient number $[2,9,35]$, or even 


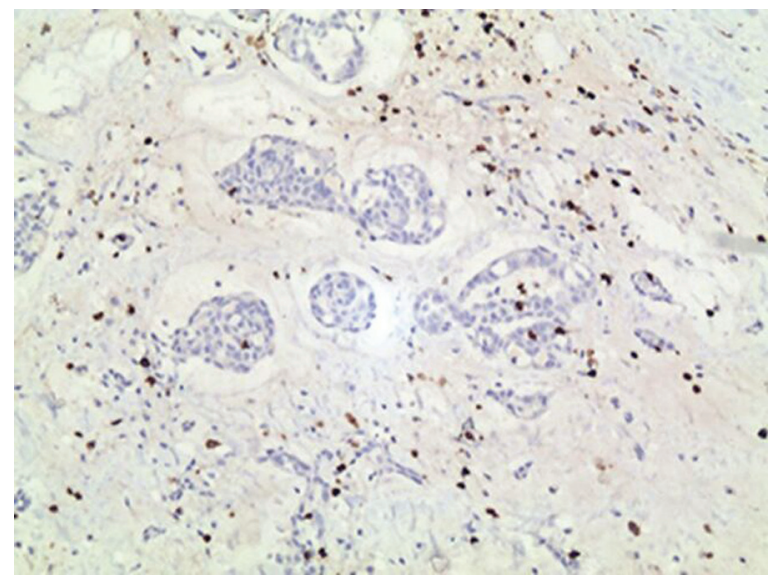

Figure 8. Weak and scattered immunoreaction to $\mathrm{CD} 3$ in glandular structures; En Vision $\times 400$.

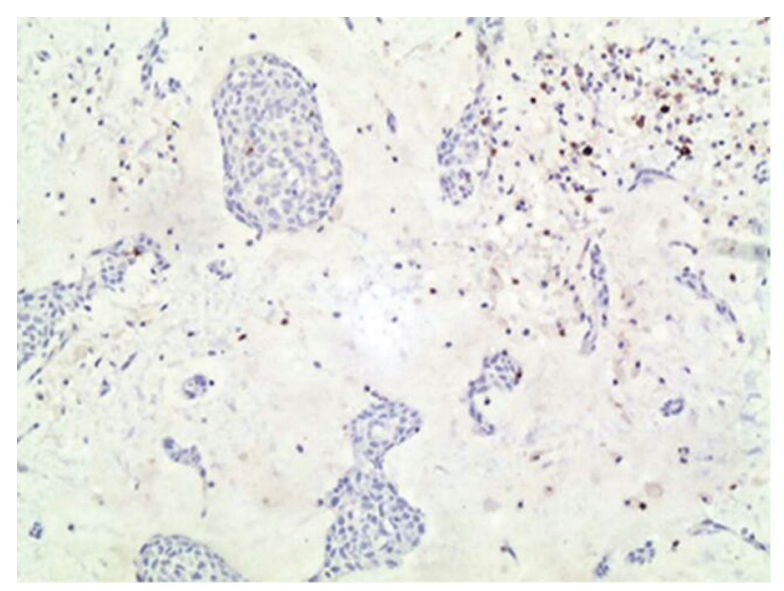

Figure 9. Weak and scattered immunoreaction to $C D 20$ in glandular structures; En Vision $\times 400$.

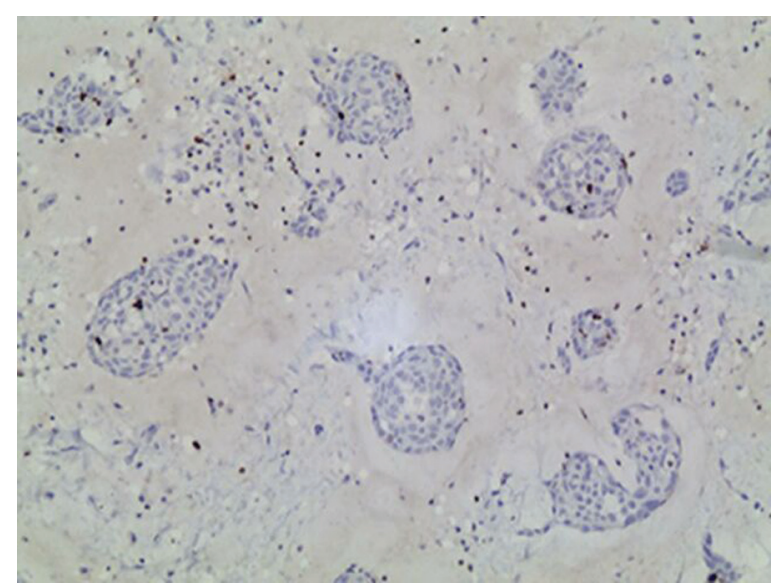

Figure 10. Expression of Ki-67 was only less than $1 \%$ in glandular structures; En Vision $\times 400$. with no patient number $[7,13,66,80]$ of glandular $\mathrm{CM}$ without patient information, with 3 intracardiac heterotopia of epithelium $[6,11,51]$, and describing a bone metastasis of glandular CM, however, the in situ CM did not show any glandular components [69]. Finally, 54 reports (30 case reports $[4,5,8,16,17,22$, $24,27,34,36-41,43-45,52,53,55,58,62,63,65$, $66,68,70,74,77], 23$ original articles [10, 12, 14, 15, $19,21,29,30,47,54,56,59-61,64,67,72,73,75$, $78,79,81,82$ ] and 1 case series [18]) were included, with 99 patients with a glandular CM (a total of 100 cases including the present patient) representing $7.4 \%$ of the $1,351 \mathrm{CM}$ patients under investigation. Of the 100 patients, 24 were males and 39 were females with a male-to-female ratio of 1:1.63, while gender could not be tracked in 37 patients. Their age was $51.2 \pm 16.4$ (range 10-78; median 53.5) years $(n=40)$. There was no age difference between male and female patients $(51.4 \pm 17.3$ years vs. $51.0 \pm 16.1$ years, $p=0.9386)$. Of the developmental patterns, $24(80 \%)$ were sporadic and $6(20 \%)$ were familial $\left(\chi^{2}=0.0000, p=1.0000\right)$. Locations of the $\mathrm{CM}$ were described in 65 patients: $46(70.8 \%)$ in the left atrium, $16(24.6 \%)$ in the right atrium and $3(4.6 \%)$ in both atria $\left(\chi^{2}=67.3, p=0.0000\right)$. The dimensions of the myxomas were $5.9 \pm 2.0$ (range 2.8-9; median 4.8) $\mathrm{cm}(\mathrm{n}=30)$. The left atrial myxoma measured $4.9 \pm 1.7$ (range 1.5-7.8; median 4.5) $\mathrm{cm}(\mathrm{n}=17)[1,15,17$, $18,24,27,34,36-38,44,45,53,62,68,73]$, and the right atrial myxomas extended $7.6 \pm 3.5$ (range 2.5-16; median 7.1) $\mathrm{cm}(\mathrm{n}=10)[4,5,8,12,18,22$, $24,39-41,58]$. The dimensions of the right atrial myxomas were much larger than that of the left $(p=0.0112)$. The weight of the myxoma was reported in 5 patients which was $41.2 \pm 38.7$ (range 5-109; median 37.5) $g(n=6)[18,22,44,65,68]$ (1 patient had biatrial myxomas weighed). The myxomas were pedicled in 9 patients $[1,22,24,34,36,37,40,68$, 73], of whom 4 patients had their pedicles measured with a length of $1.5 \pm 1.1$ (range $0.3-3.0$; median 1.3) $\mathrm{cm}(\mathrm{n}=4)$; whereas 4 myxomas were broad-based $[8,24,39,44]$. The attachment site of the myxomas was described in 40 patients, with atrial septum (fossa ovalis) being the most common attached site (Fig. 11). The locations of the glandular structures were reported in 41 cases: $37(90.2 \%)$ were at the base $[1,8,30,37,40,44,56,60,65,73,75,79], 2(5.4 \%)$ scattered [36, 60], 1 (2.4\%) central [72] and 1 (2.4\%) central and at the base of pedicle [39]. The distributions of the glandular structures were expressed in 


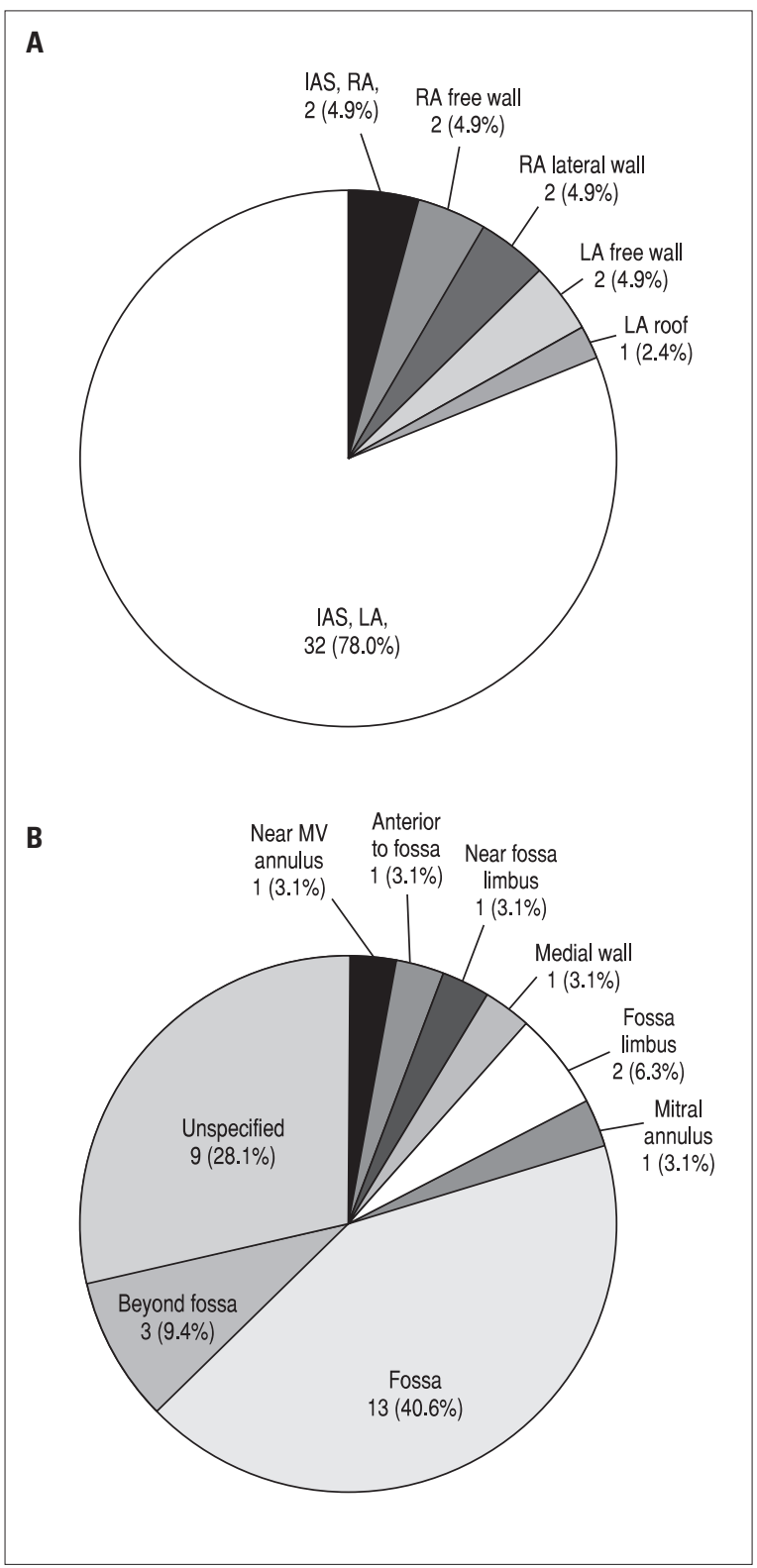

Figure 11. Distribution of attachment sites of the myxomas in (A) overall, and (B) left atrium; IAS — intraatrial septum; LA — left atrium; $\mathrm{MV}$ - mitral valve; RA — right atrium.

52 patients: 21 (40.4\%) were focal [4, 8, 12, 17, 19, $22,24,44,45,52,58,59,62,72,73], 16$ (30.8\%) were prominent $[10,14,18,30,36,37,40,43,47$, $53,60,77,82], 11(21.2 \%)$ were scattered [5, 10, $21,47,60,68,79]$, and 4 (7.7\%) were widespread/ /extensive [15, 24, 48, 64]. Development of the glandular structures were given in 28 patients: 25 (83.3\%) were well-developed $[8,12,14,17,21,24,27,36$, $38,40,43,53,64,65,73,75,79], 1$ (3.3\%) was very poorly formed [65], 2 (6.7\%) had variable structures $[22,56]$ and $2(6.7 \%)$ were pseudo-glands $[34,54]$.
In 1 patient, the glandular CM formed by irregular, angulated contours with cribriform architectures [17]. A CM of another patient showed confluent glandular structures [38]. The present patient had irregular, not very well developed glands, and confluences of glands were seen as well. Mild focal nuclear atypia [1, 65, $73,81]$ and occasional atypical mitosis [1, 17, 68, 81] were reported in 4 (4\%) patients, each. Besides, epithelial cells with an abrupt transition into myxoma cells were observed in 3 patients [14]. Malignant transformation of glandular structures in a CM was observed in $3(3 \%)$ cases $[8,43,52]$.

Histologically, typical myxoma cells are moderate amount of stellate or spindle-shaped myxoma cells, eosinophilic cytoplasm, occasional perivascular aggregates, bubbly to fibrillar stroma with focal haemorrhage, fibrin insudation and haemosiderin-laden macrophages, and absence of nuclear atypia, mitosis, or necrosis [14, 22]. Some of these glands contained luminal mucin [14]. Haemorrhagic areas, haemosiderin laden macrophages, neutrophil, leukocytes and lymphocytes were also observed in myxoid stroma [62].

Immunohistochemical studies of CMs are in 3 ways: surface lining cells, stromal myxoma cells and perivascular cells [17]. Myxoma cells were positively reactive to Factor VIII (focal, endothelium-lined area), SMA [1] and vimentin [1, 8, 37], which was observed in spindle cells of the stroma [36], neuron-specific enolase (NSE) (slightly and focally) [8, 36], S100 (a few dendric cells) $[8,37]$ and SMA (slightly and focally, sparse muscular areas) [36], and those with some muscle fibres [37]; but negative to CK, EMA, CEA, Leu 1 and desmin [1]. Negative reaction was also noted in staining with Factor VIII [36]. Matrix showed positivity to vimentin (spindle cells of the stroma) [36], vimentin [38, 40], calretinin [38, 40]; negative to Factor VIII [36], CEA [40], S100 [40], CK [40], CK7 [40] and CK20 [40]. Endothelium-lined capillaries of myxomas were positive to ulex europaeus [14], vimentin (stellate cells) [40], SMA [36], Factor VIII [36, 38], vimentin [37], CD31 [38], CD34 [38], S100 (occasional stellate cells) [40] and CEA (focally, stellate cells) [40]; but negative also to CEA [40], CK [40], CK7 [40] and CK20 [40]. The expressions of pan-CK and CEA are in keeping with the epithelial differentiation in CM. The myxoma cells were positive for SMA, but negative for desmin and S100, and therefore myofibroblastic cells were suggested as the cell of origin [3]. Myxoma cells were positive for calretinin in $75-100 \%$ of cases, but had variable positivity for 
vimentin, $\alpha_{1}$-antichymotrypsin, $\alpha_{1}$-antitrypsin, S100, SMA, desmin, synaptophysin, NSE and endothelial markers; only epithelioid structures may be positive for epithelial markers (pan-CK, CAM5.2, CK34E12, CK7, CK20, EMA and CEA) [9].

CM showed two patterns of glandular structures: glands separated from myxoma cell islands are termed as Pattern 1, and glands within the myxoma cell islands are termed as Pattern 2 [47]. Glandular structures were predominantly present at the base or the pedicle of the CM $[1,14]$. The well-developed glandular spaces were lined by a single layer of cuboidal to tall columnar cells, with the presence of scattered goblet cells [79], surrounded by amorphous extracellular myxoid material [41]. In 5.56\% (3/66), additional glandular and pseudocystic elements were found. The proteoglycan-rich myxoid and vascularised stroma also contained dendritic cells, macrophages and scattered lymphocytes [61]. The cyst-like spaces are lined by epithelium-like cells, from tiny gland-like structures to the larger cystic spaces [5]. Basal membrane or cilia can be absent in the glands [1]. Regular, columnar goblet cells indicate well-developed glandular structures [36]. In addition to cells with intracellular lumina, there are some goblet or signet ring cells with bluish cytoplasmic mucin vacuoles [38].

Secretory epithelium dispersed in a myxoid mucinous stroma may lead to a misdiagnosis as a very well-differentiated mucin secreting adenocarcinoma [43]. Glands may be composed of cells with irregular hyperchromatic nuclei of various size and shape and distinct large nucleoli indicating the potential transferrable and differentiating capacities of CM [17]. Focal stratification, tuft formations and micropapilae were seen in the glandular structures [1]. Rupture of glands into the stroma [22], apparent transition from flattened and spindled myxoma cells to plump glandular cells [22], transition from typical myxoma cells to cord-like myxoma cells [60], paradoxical transition from epithelial cells to myxoma cells [14] and direct links between glands and perivascular myxoma cells [60] were also observed. Small areas of benign glands in close contact with the adenocarcinoma and metastases to the lung, kidney, left adrenal gland and bones were reported [20].

The glandular epithelium has been histochemically and immunohistochemically identified a gastrointestinal or enteric nature of the epithelium. Periodic acid Schiff (PAS)-positive cytoplasmic globules and strong immunoreactivity against cytokeratin were de- monstrated in the cuboidal and low columnar simple epithelium [12]. PAS and Alcian blue (AB) stainings were positive in 3 places of glandular structures of myxoma: the gland lumina, the goblet cells and the brush border, where mucus was generated [38]. Basal positivity for PAS and apical positivity for $A B$ and mucicarmine were noted [40].

Immunohistochemically some endothelial markers, such as CD31, CD34 and Factor VIII, are present in myxoma cells. Positive staining has also been reported for $\mathrm{S100}$, calretinin, vimentin, desmin, smooth muscle myosin, CD56, $\alpha_{1}$-antitrypsin and $\alpha_{1}$-antichymotrypsin [25], and interleukin-6 [27]. Willebrand factor was only detected in endothelial cells lining vascular channels and deep invaginations of surface papillae [53].

Glandular structures showed positive reactions to CK (50\%), EMA (focal, luminal), CEA (50\%), Leu 1; Ulex europaeus (epithelial cells and erythrocytes) [1], CK (glandular epithelium) [36, 40, 43], CEA (apical surface cytoplasm) [36, 38, 40], pan-CK [38], CD31 (focal) [38], S100 (focal glands) [40], calretinin [40], CK7 [38, 40], vimentin (cytoplasm) [40], CA19.9 (cytoplasmic membranes, mainly at the apical side and intracytoplasmic vacuoles) [36], mesothelioma marker HBME-1 (focal) [38] and interleukin-8 [27]; while negative to Factor VIII [14], NSE (cytoplasm, slightly) [36], pan-CK [37], CK20 [38, 40], calretinin [38], CEA [37], CD68 [37] and chromogranin A $[36,37]$. The histopathology of the present case was compatible with the current literature.

Positivity to CEA is a characteristic of endodermal origin, indicating that the myxoma cells are of capacities of the endoderm cells [29]. The satellite cells express simultaneously $\mathrm{S} 100$ and synaptophysin (Syn), suggesting the origin of myxoma may be associated with the endocardial sensory nerve tissue [13]. The staining of CK reactivity was observed mostly in the surface lining cells [19]. In the case with glandular differentiation, the positivity was both within the glandular component and the surrounding myxoma cells [17]. Vimentin, EMA, pan-CK, CK7, CEA and calretinin were positive in the glandular structures and variably in stellate cells and blood vessels [40]. Pan-CK and CK7 were strongly positive along with EMA and CEA, whereas CK20 was negative in the glandular structures, indicating a possibility of entrapped foregut rest origin of CM [40]. 
p53 protein immunoreactivity could be an indicator for discrimination between neoplastic and reactive mesothelium [49]. Generally, the regular glandular structures showed rare nuclear p53 staining. Foregut remnants, bronchial or alveolar epithelium, mesothelium and germ cells have been supposed as the origin of the glandular structures. Uncommon proliferative activity was considered "reactive" atypia, in the CM with glandular differentiation, the mitotic index and degree of atypia, with striking variation in size and shape of nuclei were more likely an early malignant behaviour than reactive process [17]. Ki-67 represents the proliferation rate, and studies of $\mathrm{CM}$ on this aspect revealed a slow proliferative rate [50]. Pucci et al. [48] reported that a very low proliferative activity $(<2 \%)$ was detected in glandular cells of case 3 by means of Ki-67 immunoreactivity. Berger et al. [8] noted that the proliferation rate with Ki- 67 was less than $10 \%$ in the benign glands of $\mathrm{CM}$ and about $80 \%$ in the malignant glands of the adenocarcinoma and the systemic metastases.

The myxoma cells bear some similarities with mesothelial cells [38]. Expressions of both epithelial and vascular antigens reflect the multipotential nature of myxoma cells. Heterotopia in CM provides evidence to the theory of a pluripotent reserve cell line of origin arising from embryonic rests [42]. Differential diagnoses of CM include intracardiac thrombus, cardiac excrescence and other primary or metastatic cardiac neoplasms [9]. Immunohistochemical study can meet the satisfaction of the differential diagnosis [9]. Glandular CM have to be distinguished from a metastatic carcinoma as small areas of benign glands resemble adenocarcinoma $[20,46]$. Nevertheless, atypia and mitosis are rarely present in the former [71]. CM, renal angiofibrolipomas and thyroid adenoma presented considerable atypism at the same time, and therefore $\mathrm{CM}$ may be in accord with the hamartoma in view of histogenesis [31]. Side-by-side malignant and benign glands could be detected in the small transitional zone between myxoma and adenocarcinoma, indicating transferable capacities of the myxoma cells [8].

\section{CONCLUSIONS}

Glandular CMs are morphologically characterised by base locations, focal distributions and well-developed structures in most cases with low proliferative and metastatic natures. They might derive from entrapped embryonal rests of a precursor cell toward epithelial and mesenchymal lineages. Differentiated glandular structures present in CM cells, other than in the thrombus, support the neoplastic origin of CM. Well-developed glands with basement membranes, junctional complexes and apical secretory granules revealed by ultrastructural studies also support the neoplastic origin of CM.

\section{REFERENCES}

1. Abenoza P, Sibley RK (1986) Cardiac myxoma with glandlike structures. An immunohistochemical study. Arch Pathol Lab Med, 110: 736-739.

2. Acebo E, Val-Bernal JF, Gómez-Román JJ, Revuelta JM (2003) Clinicopathologic study and DNA analysis of 37 cardiac myxomas: a 28-year experience. Chest, 123 : 1379-1385.

3. Akyıldız EÜ, Tolgay E, Öz B, Yılmaz R, Koç S (2006) Cardiac myxoma: an unusual cause of sudden death in childhood. Turkish J Pediatr, 48: 172-174.

4. Alarcón-Galván G, Sepúlveda-Rodríguez LA, Hernández-Batres F, Flores Gutiérrez JP, Guajardo RG, Rendón Elias FG, Quintana OB, Rodríguez JA (2010) Mixoma auricular con elementos glandulares. Patología Rev Latinoam, 48: 111-114.

5. Anderson WA, Dmytryk ET (1946) Primary tumor of the heart containing epithelium-like elements. Am J Pathol, 22: 337-349.

6. Ariza S, Rafel E, Castillo JA, Garcia-Canton JA (1978) Intracardiac heterotopia: mesenchymal and endodermal. $\mathrm{Br}$ Heart J, 40: 325-327.

7. Basso C, Valente M, Poletti A, Casarotto D, Thiene G (1997) Surgical pathology of primary cardiac and pericardial tumors. Eur J Cardiothorac Surg, 12: 730-737; discussion 737-738.

8. Berger MD, Schneider J, Ballmer PE, Eckhardt BP, Dommann-Scherrer C (2013) Mucin-producing adenocarcinoma arising in an atrial myxoma. Ann Diagn Pathol, 17: 104-107.

9. Bordalo AD, Alves I, Nobre AL, Silva F, Lemos A, Serpa C, Fernandes A, Cravino J (2012) New clinical aspects of cardiac myxomas: a clinical and pathological reappraisal. Rev Port Cardiol, 31: 567-575.

10. Burke AP, Virmani R (1993) Cardiac myxoma. A clinicopathologic study Am J Clin Pathol, 100: 671-680.

11. Cappell MS, Lapin S, Rose M (2008) Large right atrial myxoma containing gastric heterotopia presenting with dyspnea and bilateral leg edema due to pulmonary emboli and cardiovascular obstruction: the first known report of gastric heterotopia in the cardiovascular system. Dig Dis Sci, 53: 405-409.

12. Chan KW, Lee WT, Lam KY, Chan ACL, Fu KH (1997) Cardiac tumors in Hong Kong: a clinicopathological study of 66 cases. Int J Surg Pathol, 4: 227-232.

13. Chen SY, Ming YH (2010) Clinical pathological and immunohistochemical studies on 30 cardiac myxoma patients. J Rare Uncomm Dis, 17: 19-21.

14. Chopra P, Ray R, Singh MK, Venugopal P (2003) Cardiac myxoma with glandular elements: a histologic, histochemical, and immunohistochemical evaluation. Indian Heart J, 55: 182-184.

15. Curschellas E, Toia D, Borner M, Mihatsch MJ, Gudat F (1991) Cardiac myxomas: immunohistochemical study of 
benign and malignant variants. Virchows Arch A Pathol Anat Histopathol, 418: 485-491.

16. de Morais C, Falzoni R, Alves VA (1988) Myocardial infarct due to a unique atrial myxoma with epithelial-like cells and systemic metastases. Arch Pathol Lab Med, 112: 185-190.

17. den Bakker MA, Dinjens WN, Bekkers JA (2006) Cardiac myxoma with atypical glandular component, report of a case. Histopathology, 48: 206-208.

18. Deshpande A, Kumar S, Chopra P (1994) Recurrent, biatrial, familial cardiac myxomas Int J Cardiol, 47: 71-73.

19. Deshpande A, Venugopal P, Kumar AS, Chopra P (1996) Phenotypic characterization of cellular components of cardiac myxoma: a light microscopy and immunohistochemistry study. Hum Pathol, 27: 1056-1059.

20. Eckhardt BP, Dommann-Scherrer CC, Stuckmann G, Zollikofer CL, Wentz KU (2003) Giant cardiac myxoma with malignant transformed glandular structures. Eur Radiol, 13: 2099-2102.

21. Fine G, Morales A, Horn RC Jr (1968) Cardiac myxoma. A morphologic and histogenetic appraisal. Cancer, 22: 1156-1162.

22. Frishman W, Factor $S$, Jordan A, Hellman C, Elkayam U, LeJemtel T, Strom J, Unschuld H, Becker R (1979) Right atrial myxoma: unusual clinical presentation and atypical glandular histology. Circulation, 59: 1070-1075.

23. Glasser SP, Bedynek JL, Hall RJ, Hopeman AR, Treasure RL, McAllister HA Jr, Esterly JA, Manion WC, Sanford HS (1971) Left atrial myxoma. Report of a case including hemodynamic, surgical, histologic and histochemical characteristics. Am J Med, 50: 113-122.

24. Goldman BI, Frydman C, Harpaz N, Ryan SF, Loiterman D (1987) Glandular cardiac myxomas. Histologic, immunohistochemical, and ultrastructural evidence of epithelial differentiation. Cancer, 59: 1767-1775.

25. Hernández-Bringasa O, Ortiz-Hidalgoa C (2013) Características histopatológicas e inmunohistoquímicas de los mixomas cardiacos. Arch Cardiol Mex, 83: 199-208.

26. http://case.medlive.cn/all/case-imageology/show27611_131.html.

27. Isobe $\bar{N}$, Kanda T, Sakamoto H, Morishita Y, Suzuki T, Kobayashi I (1996) Myocardial infarction in myxoma patients with normal coronary arteries: case reports. Angiolog, 47: 819-823.

28. Jin XZ, Qian YC, Ma HH, Zhang TH, Huang FL (1993) Morphological study of cardiac myxomas with glandular structures: Histochemical, immunohistochemical and electron-microscopic study of 26 cases. Bull Jinling Hosp, 6: 325-328, 386

29. Jin XZ, Qian YC, Ma HH, Zhang TH, Huang FL (1994) Morphological study of cardiac myxomata with adenoidlike structures Med J Chin PLA, 19: 351-354.

30. Johansson $L$ (1989) Histogenesis of cardiac myxomas. An immunohistochemical study of 19 cases, including one with glandular structures, and review of the literature. Arch Pathol Lab Med, 113: 735-741.

31. Kaneko H, Murohashi T, Katano A, Hojo H, Ishikawa $S$ (1976) Atrial myxoma associated with multiple hamartomas. Acta Pathol Jpn, 26: 603-610.

32. Kelly M, Bhagwat AG (1972) Ultrastructural features of a recurrent endothelial myxoma of the left atrium. Arch Pathol, 93: 219-226.

33. Krikler DM, Rode J, Davies MJ, Woolf N, Moss E (1992) Atrial myxoma: a tumour in search of its origins. Br Heart J, 67: 89-91.
34. Lazos-Ochoa M, Cruz-Gordillo AG, Murguía-Perez M (2011) Synchronic hepatocellular carcinoma with atrial myxoma. A case report. Invest Clin, 52: 170-174.

35. Li Y, Pan Z, Ji Y, Sheppard M, Jeffries DJ, Archard LC, Zhang H (2003) Herpes simplex virus type 1 infection associated with atrial myxoma. Am J Pathol, 163: 2407-2412.

36. Lindner V, Edah-Tally S, Chakfé N, Onody T, Eisenmann B, Walter P (1999) Cardiac myxoma with glandular component: case report and review of the literature. Pathol Res Prac, 195: 267-272.

37. Liu Y, Xu ML (2006) Cardiac myxoma with glandular component: case report. Chin Med J (Engl), 119: 174-176.

38. Lloreta J, Juanpere N, Riverola A, Dallari D, Cañas MA, Pijuan L, Baró T, García P, Serrano S (2013) Cardiac myxoma with glandular differentiation: an immunohistochemical and ultrastructural study. Ultrastruct Pathol, 37: 77-82.

39. Luo J, Zhao GH (2001) A case of right atrial myxoma of glandular type. J China-Japan Friendship Hosp, 15: 207.

40. Mallick SR, Das P, Shukla B, Kothari S, Devagourou V, Ray R (2010) Right atrial myxoma with glandular differentiation: a rare entity in pediatric age group. Ann Pediatr Cardiol, 3: 159-162.

41. Meier MR, Dietl CA, Fischer EG, Raizada V (2005) Huge right atrial myxoma with tricuspid valve endocarditis. Chirurgia, 18: 395-398.

42. Miller DV, Tazelaar HD, Handy JR, Young DA, Hernandez JC (2005) Thymoma arising within cardiac myxoma. Am J Surg Pathol, 29: 1208-1213.

43. Moiyadi AV, Moiyadi AA, Sampath S, Kalpana SR, Mahadevan A, Shankar SK, Srikanth SG (2007) Intracranial metastasis from a glandular variant of atrial myxoma. Acta Neurochir (Wien), 149: 1157-1162.

44. Namura O, Saitoh M, Moro H, Watanabe H, Sogawa M, Nishikura K, Hayashi J (2007) A case of biatrial multiple myxomas with glandular structure. Ann Thorac Cardiovasc Surg, 13: 423-427.

45. Pernick N (2007) 22 March 2007: Case of the Week \#78. http://www.pathologyoutlines.com/caseofweek/ case200778.htm.

46. Prasenjit D, Bhaskar S, Kothari S, Devagourou V, Ruma R, Saumya M. Right atrial myxoma with glandular differentiation: a rare entity in pediatric age group. http:// rockyourpaper.org/article/right-atrial-myxoma-with-glandular-differentiation-a-rare-entity-in-pediatric-age-group-747a0b911ff7cc07cba30f2998936b1c.

47. Pucci A, Bartoloni G, Tessitore E, Carney JA, Papotti M (2003) Cytokeratin profile and neuroendocrine cells in the glandular component of cardiac myxoma. Virchows Arch, 443: 618-624.

48. Pucci A, Gagliardotto P, Zanini C, Pansini S, di Summa M, Mollo F (2000) Histopathologic and clinical characterization of cardiac myxoma: review of 53 cases from a single institution. Am Heart J, 140:134-138.

49. Ramael M, Lemmens G, Eerdekens C, Buysse C, Deblier I, Jacobs W, van Marck E (1992) Immunoreactivity for p53 protein in malignant mesothelioma and non-neoplastic mesothelium. J Pathol, 168: 371-375.

50. Roskell DE, Biddolph SC (1999) Proliferating cell nuclear antigen expression grossly over-estimates cellular proliferation in cardiac myxomas, Eur J Med Res, 4: 105-106.

51. Sasaki K, Parwani AV, Demetris AJ, Sasatomi E (2010) Heterotopic breast epithelial inclusion of the heart: report of a case. Am J Surg Pathol, 34: 1555-1559. 
52. Scarpelli M, Montironi R, Ricciuti R, Vecchioni S, Pauri F (1997) Cardiac myxoma with glandular elements metastatic to the brain 12 years after the removal of the original tumor. Clin Neuropathol, 16: 190-194.

53. Schmitt-Gräff A, Borchard F (1992) Cardiac myxoma with a cytokeratin-immunoreactive glandular component. Pathol Res Pract, 188: 217-221; discussion 221-225.

54. Scholz J, Suárez C, Mota JD (2007) Mixomas cardíacos: estudio morfológico e inmunohistoquímico de 50 biopsias. Gac Méd Caracas, 115: 126-137.

55. Schultrich S (1990) Histogenesis of cardiac myxoma based on a myxoma with glandular structures. Pathologe, 11: 220-223.

56. Shang JF, Chen D, Wu Y, Fang W, Wang W, Shi FR, Xiao L, Zhang HX (2010) The clinicopathologic analyses on cardiac myxoma with glandular structure J Cardiovasc Pulm Dis, 29: 493-495.

57. Shehata BM, Burke AP, Tazelaar H, Patel CR (2004) Tumours of the heart: benign tumours with myocyte differenciation. In: Travis WD, Brambilla E, Muller-Hermelink HK, Harris CC eds. World Health Organization classification of tumours. Pathology and genetics of tumours of the lung, Pleura, Thymus and Heart. IARC Press, Lyon, pp. 254-270.

58. Shroff S, Huang Y, Balos L, Chen F (2012) Immunohistochemical characterization of cardiac myxoma, glandular variant, in a 75-year-old man. Surgical Pathology (Gastrointestinal, Genitourinary, Liver, Pancreas, Renal, Bone \& Soft Tissue Cardiovascular), Friday Session 3, November 2, 2012. Am J Clin Pathol,138: A309.

59. Sipos B, Járay B, Richter T (1995) Glandular myxoma of the heart. rv Hetil, 136: 1333-1335.

60. Song LF, Zhang ZQ, Huang WY (1983) Morphologic study of cardiac myxomas. Chin Med J (Engl), 96: 7-12.

61. Steger CM, Hager T, Ruttmann E (2012) Primary cardiac tumours: a single-center 41-year experience. ISRN Cardiology, 2012: 906109. doi: 10.5402/2012/906109

62. Taşemir A, Canöz Ö, Taşemir K (2011) Cardiac myxoma with glandular component. Erciyes Týp Dergisi (Erciyes Med J), 33: 341-344.

63. Tataroğlu C (2013) Glandular cardiac myxoma with associated human papilloma virus infection: case report. Turkiye Klinikleri J Cardiovasc Sci, 25: 99.

64. Terracciano LM, Mhawech P, Suess $K$, D'Armiento $M$, Lehmann FS, Jundt G, Moch H, Sauter G, Mihatsch MJ (2000) Calretinin as a marker for cardiac myxoma. Diagnostic and histogenetic considerations. Am J Clin Pathol, 114: 754-759.

65. Thornton CM, Walsh MY (1993) Glandular differentiation in cardiac myxomata. Ir J Med Sci, 162: 95-97.

66. Tian XA, Xing J, Ma QL, Tian L (2011) The pathological and immunohistochemical studies of cardiac myxoma. Chin J Ethnomed Ethnopharm, 20: 9.
67. Tószegi A (1990) Morphology of cardiac myxomas. Morphol Igazsagugyi Orv Sz, 30: 43-50.

68. Tsao TY, Wu CW, Wei J (2008) Cardiac myxoma with malignant glandular component and high serum CA125: immunohistochemical finding of one case and literature review. Tungs' Med J, 2: 88-94.

69. Uppin SG, Jambhekar N, Puri A, Kumar R, Agarwal M, Sanghvi D (2011) Bone metastasis of glandular cardiac myxoma mimicking a metastatic carcinoma. Skeletal Radio, 40: 107-111.

70. Vacek R (1963) Intracardial hamartoblastoma. Zentralbl Allg Pathol, 104: 383-391.

71. Virmani R (2001) Tumours and tumor-like lesions of the heart and great vessels. Chapter 12. In: Virmani R, BurkeA, Farb A, Atkinson JB eds. Cardiovascular pathology. $2^{\text {nd }}$ Ed. WB Saunders Company, St. Louis, MO, pp. 424-468.

72. Wang HY, Zhang XB, Zheng JJ, Deng Y, Wang YL, Song YX, Liu L, Wang M (2006) Clinicopathologic features of cardiac myxoma: a report of 47 cases Ai Zheng, 25: 892-895.

73. Wang JG, Li YJ, Liu H, Li NN, Zhao J, Xing XM (2012) Clinicopathologic analysis of cardiac myxomas: Seven years' experience with 61 patients. J Thorac Dis, 4: 272-283.

74. Wang JG, Xiang FG (2010) A case of left atrial glandular myxoma. Chin J Clin Thorac Cardiovasc Surg, 17: 422.

75. Wang XY (1993) Immunohistochemical study and evaluation of histogenesis of cardiac myxoma Zhonghua Bing Li Xue Za Zhi, 22: 262-264.

76. Webpathology: atrial myxoma. http://www.webpathology. com/image. asp? case $=516 \& n=5$.

77. Widder W, Schneider J, Schanz U (1985) Endocardial myxoma with glandular structures and its relation to the AV nodal tumor. Study of its histogenetic significance. Pathologe, 6: 303-307.

78. Yin LB, Yang L, Zhu GR, Li YN, Wang FH (2000) The experience of diagnosis and treatment of intracardiac myxomas J Norman Bethune Univ Med Sci, 26: 222.

79. Zhang M, Ding L, Liu Y, Xue L (2013) Cardiac myxoma with glandular elements: A clinicopathological and immunohistochemical study of five new cases with an emphasis on differential diagnosis. Pathol Res Pract, 2013 Oct 26. doi: pii: S0344-0338(13)00334-8. 10.1016/j.prp.2013.09.018. 'Epub ahead of print].

80. Zhang PF, Anderson WR (1998) Pathologic study of cardiac myxomas and its clinical significance. J Fujian Med Univ, 32: 32-34.

81. Zhang XH, Zhao F, Li SH (1995) Immunohistochemical and electron microscopic observations of atrial myxomas Chin J Diagn Pathol, 2: 162-163.

82. Zheng JJ, Geng XG, Wang HC, Yan Y, Wang HY (2013) Clinical and histopathological analysis of 66 cases with cardiac myxoma Asian Pac J Cancer Prev, 14: 1743-1746. 